\title{
Contribution of Soft Copper Particle on Work Hardening Behavior in Ferritic Iron
}

\author{
Yuta IMANAMI, ${ }^{1)}$ Masahiro MURAKAMI, ${ }^{1)}$ Nobuo NAKADA, ${ }^{2)}$ Toshihiro TSUCHIYAMA ${ }^{2)}$ and \\ Setsuo TAKAKI ${ }^{2}$ \\ 1) Graduate Student, Kyushu University, 744 Motooka, Nishi-ku, Fukuoka 819-0395 Japan. \\ 2) Department of Materials Science and Engineering, Kyushu University, 744 Motooka, Nishi-ku, Fukuoka $819-0395$ Japan.
}

(Received on January 29, 2009; accepted on April 4, 2009)

\begin{abstract}
Tensile tests were performed for two kinds of model alloys containing soft Cu particles or hard VC particles. Work hardening rate was obviously smaller in the $\mathrm{Cu}$ particle dispersion steel than in the VC particle dispersion steel. TEM observation for the cold-rolled specimens revealed the different dislocation arrangement; high density dislocations are introduced around the carbide particles in the VC steel, while dislocations are less accumulated in the $\mathrm{Cu}$ steel because dislocations can pass through $\mathrm{Cu}$ particles during plastic deformation.
\end{abstract}

KEY WORDS: work hardening; copper; particle dispersion; dislocation accumulation.

\section{Introduction}

In terms of recycle of scrap iron, useful application of $\mathrm{Cu}$ as a tramp element has recently been attempted. $\mathrm{Cu}$ can dissolve into austenite phase up to 10 mass $\%$ at around $1600 \mathrm{~K}$, while the solubility in ferrite is very small. Therefore, $\mathrm{Cu}$ precipitates within the ferrite matrix by aging treatment after the solution treatment in austenite region. Since the growth rate of $\mathrm{Cu}$ particles in Ostwald ripening process $^{1)}$ is much slower than that of cementite, ${ }^{2)}$ the dispersion of very fine $\mathrm{Cu}$ particles can be easily obtained. In addition to such a fine dispersion, it is also important to note that the interaction between $\mathrm{Cu}$ particle and dislocations is smaller than that carbide particle does. Hard carbide particles generally have strong repulsive interaction with dislocations, and thus, the dislocation has to leave dislocation loops to bypass the particle during plastic deformation of material (Orowan mechanism), ${ }^{3)}$ except when its size is too small. On the other hand, the interaction of dislocation and $\mathrm{Cu}$ particle is known to be attractive because $\mathrm{Cu}$ particles are softer than the iron matrix in terms of shear modulus. This enables dislocations to cut and pass through $\mathrm{Cu}$ particle (Cutting mechanism). As a result, the increment of yield strength in $\mathrm{Cu}$ dispersion steels is influenced by not only the spacing of dispersed particles but also the size of particles because the resistance to cutting by dislocation depends on the particle size. ${ }^{1)}$ Since the interaction of dispersed particles and dislocations would give some influence on the development of dislocation substructure, the difference between $\mathrm{Cu}$ and carbide particles should appear more clearly in the work hardening behavior rather than the yielding behavior. In this study, two types of model steel were prepared: steels containing hard VC particles and soft $\mathrm{Cu}$ particles at the same amount and the same size. Tensile tests were carried out for the steels, and then work hardening behavior was compared in connection with the development of dislocation structure.

\section{Experimental Procedure}

The chemical compositions of $\mathrm{Fe}-\mathrm{V}-\mathrm{C}$ alloy (VC steel) and $\mathrm{Fe}-\mathrm{Cu}$ alloy $(\mathrm{Cu}$ steel) used in this study are listed in Table 1. In order to control the particle size and ferrite grain size to be similar in both steels, different heat treatment was carried out for each steel (Figs. 1(a), 1(b)). The VC steel was firstly subjected to the solution treatment at $1473 \mathrm{~K}$ for $1.8 \mathrm{ks}$ followed by water quenching to obtain martensitic structure, and then tempered at $873 \mathrm{~K}$ for $1.8 \mathrm{ks}$ to disperse VC particles uniformly within martensite matrix. After that, the tempered VC steel was reheated to $1273 \mathrm{~K}$ in (austenite + VC) two phase region, kept for $60 \mathrm{~s}$ at the temperature, and then furnace-cooled to cause ferritic transformation. On the other hand, the $\mathrm{Cu}$ steel was solution-treated at $1173 \mathrm{~K}$ for $0.6 \mathrm{ks}$ (austenite single phase region), and then aged at $873 \mathrm{~K}$ for $145.8 \mathrm{ks}$ (ferrite $+\mathrm{Cu}$ region) to make $\varepsilon-\mathrm{Cu}$ (fcc) particles disperse within ferrite matrix. The volume fraction of $\mathrm{VC}$ particles in the $\mathrm{VC}$ steel is $1.2 \%$ when the carbon is fully precipitated as VC carbide, while that of $\mathrm{Cu}$ particles in the $\mathrm{Cu}$ steel is $1.5 \%$ under the aging condition of $873 \mathrm{~K}$.

The microstructure was observed with an optical and a transmission electron microscope. Crystallographic orienta-

Table 1. Chemical compositions of materials used in this study (mass \%).

\begin{tabular}{c|c|c|c|c|c|c|c|c|c}
\hline \hline & $\mathrm{C}$ & $\mathrm{Si}$ & $\mathrm{Mn}$ & $\mathrm{P}$ & $\mathrm{S}$ & $\mathrm{V}$ & $\mathrm{Cu}$ & $\mathrm{N}$ & $\mathrm{Fe}$ \\
\hline VC steel & 0.175 & 0.07 & 0.07 & 0.004 & 0.001 & 0.84 & 0.014 & 0.003 & bal. \\
\hline Cu steel & 0.007 & 0.01 & 0.008 & 0.001 & 0.001 & - & 1.98 & 0.004 & bal. \\
\hline \hline
\end{tabular}


(a)

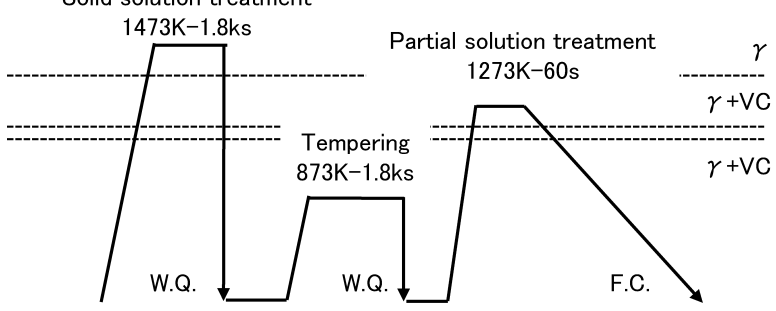

(b) Solid solution treatment

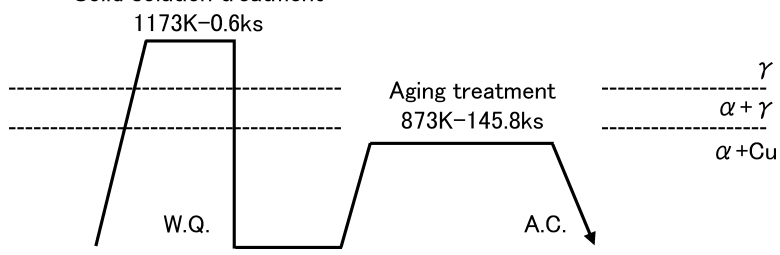

Fig. 1. Heat treatment routes for (a) VC steel and (b) Cu steel.

tion of ferrite matrix was identified by means of the electron back scattering diffraction (EBSD) method using a scanning electron microscope. The data obtained by EBSD method were analyzed with $\mathrm{OIM}^{\mathrm{TM}}$ system. Tensile testing was carried out at room temperature at the initial strain rate of $1.0 \times 10^{-3} \mathrm{~s}^{-1}$ for round-bar test pieces with a gage dimension of $\phi 3 \mathrm{~mm} \times 10 \mathrm{~mm}$. The development of dislocation substructure was observed with a TEM for specimens cold-rolled at room temperature up to $70 \%$ thickness reduction. Dislocation density in ferrite matrix was evaluated by $\mathrm{X}$-ray diffraction method using $\mathrm{Co}-\mathrm{K} \alpha$ radiation in accordance with Eq. (1), where $b$ is the burgers vector $(0.25 \mathrm{~nm})$ and $\varepsilon$ is the local strain obtained by Hall-Williamson's method. ${ }^{4)}$

$$
\rho=\frac{14.4 \times \varepsilon^{2}}{b^{2}}
$$

\section{Results and Discussion}

\subsection{Microstructure of VC Steel and Cu Steel}

Figure 2 represents optical micrographs (OMs) and crystallographic orientation imaging maps (OIMs) of the $\mathrm{VC}$ steel and $\mathrm{Cu}$ steel. The black lines in the OIMs correspond to high angle boundaries with misorientation angle larger than 15 degrees. Dislocation density of the steels is also shown in each OM. Both steels have equiaxial-grained ferritic structure with low dislocation density. Comparison of the OMs and the OIMs indicates that most of the grain boundaries observed in OMs are high angle boundaries and that no significant texture is formed in both steels. The average ferrite grain size measured by quadrature method ${ }^{5)}$ is around $23 \mu \mathrm{m}$ in both steels. Figure 3 is TEM images showing the dispersion of $\mathrm{VC} \mathrm{(a)} \mathrm{and} \mathrm{Cu}$ (c) particles and the histograms of their size distribution (b) (d) in each steel. It is found that there is no large difference in the shape and dispersion between both particles; they have roughly spherical shape and disperse uniformly within ferrite matrix with low dislocation density. The average particle sizes of VC and $\mathrm{Cu}$ particles were measured at $39 \mathrm{~nm}$ (b) and $34 \mathrm{~nm}$ (d), respectively. The substantial difference in the two kinds of particles is their strength. Although the critical cutting

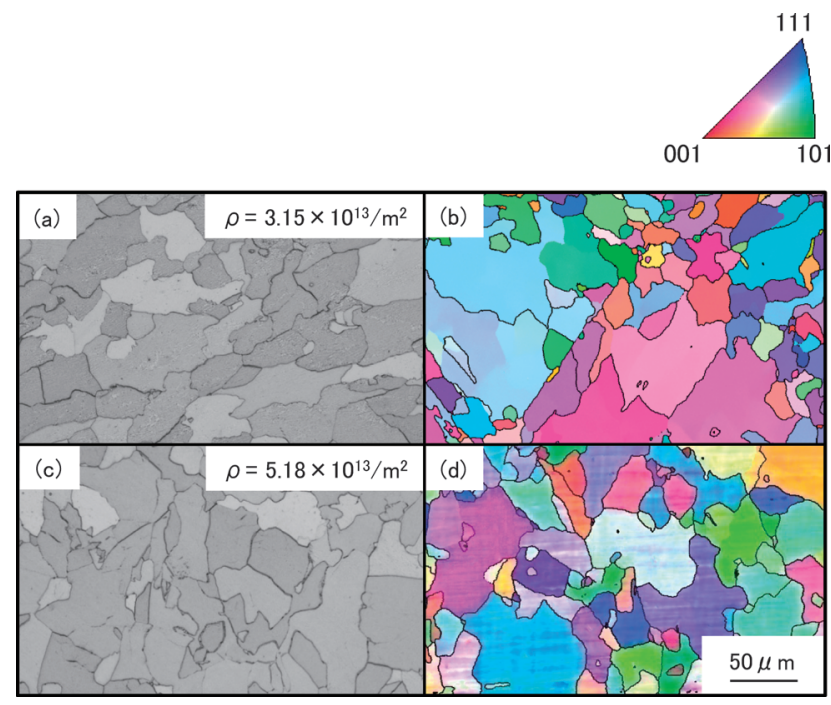

Fig. 2. Optical micrographs and orientation imaging maps of $\mathrm{VC}$ steel (a), (b) and Cu steel (c), (d).

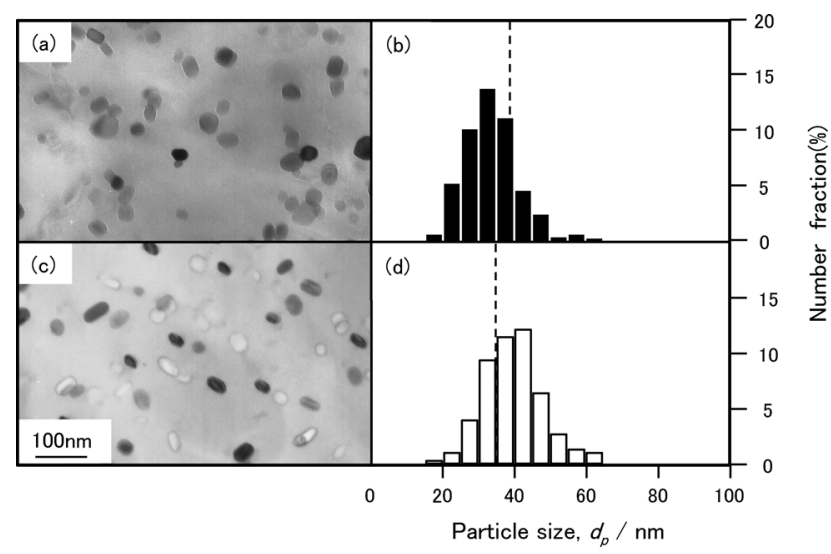

Fig. 3. TEM images and size distributions of $\mathrm{VC}(\mathrm{a}),(\mathrm{b})$ and $\mathrm{Cu}$ (c), (d) particles.

shear stress of the dispersed particles can not be directly measured, VC carbide should be markedly stronger than $\mathrm{Cu}$ $(\varepsilon-\mathrm{Cu})$ particle because Vickers hardness of VC carbide single crystal and $\varepsilon$ - $\mathrm{Cu}$ are $\mathrm{Hv} 2800^{6)}$ and $\mathrm{Hv} 40^{7)}$, respectively. It should be mentioned that even hard carbide particles could be cut by shear stress when its size is smaller than the critical cutting size which depends on the misfit strain. ${ }^{8)}$ In this study, the size of VC carbide ( $39 \mathrm{~nm}$ ) is sufficiently large to cause bypassing without cutting.

\subsection{Difference in Tensile Behavior between VC Steel and $\mathrm{Cu}$ Steel}

Figure 4 shows nominal stress-strain curves of VC steel and $\mathrm{Cu}$ steel. It is clear that work hardening behavior is completely different between the two steels although the yield stress is almost the same. The work hardening rate at the stage of $5 \%$ strain in VC steel is twice as large as that in $\mathrm{Cu}$ steel. According to the Ashby's theory, ${ }^{9}$ ) work hardening rate of material containing second phase particles is expressed as a function of volume fraction and size of the particles. However, the significantly lower work hardening behavior in $\mathrm{Cu}$ steel can not be explained by that theory. This result suggests that the soft $\mathrm{Cu}$ particles have a weaker interaction with dislocations than the hard carbide particles, 


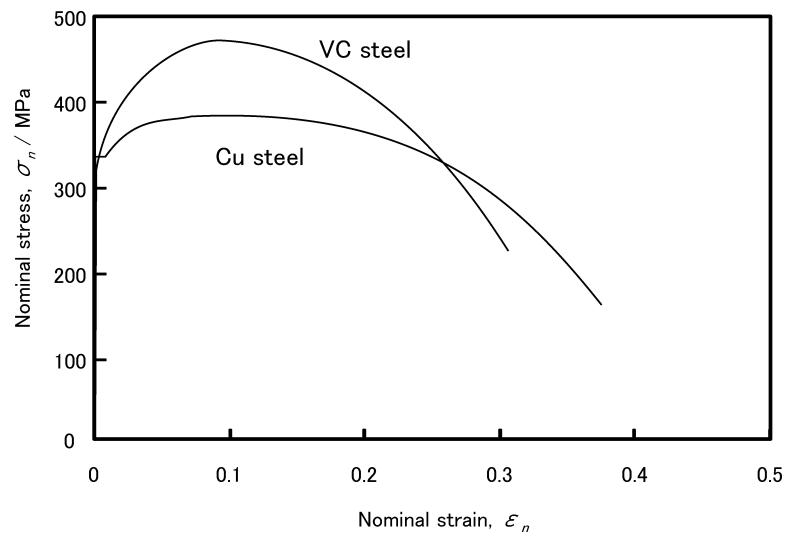

Fig. 4. Nominal stress-nominal strain carves of $\mathrm{Cu}$ steel and $\mathrm{VC}$ steel.

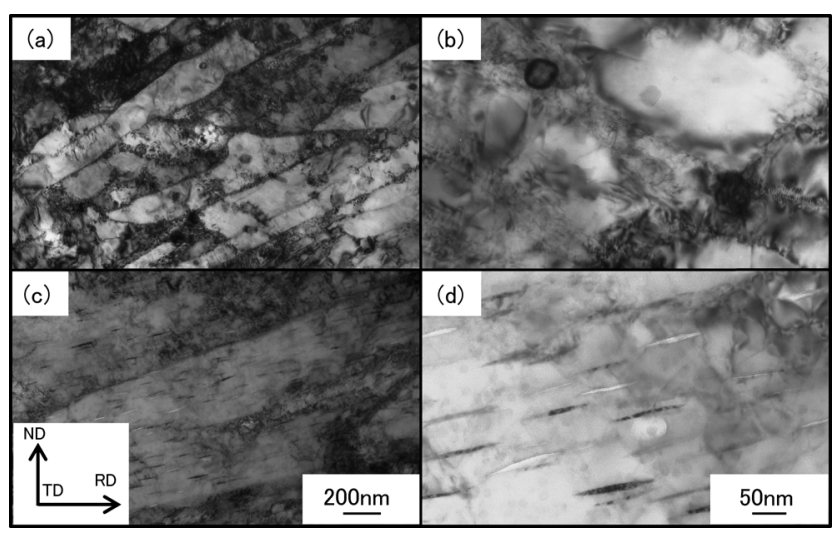

Fig. 5. TEM micrographs of $70 \%$ cold-rolled VC steel (a), (b) and $\mathrm{Cu}$ steel (c), (d).

and this leads to the less effect on the dislocation accumulation during tensile deformation in the $\mathrm{Cu}$ steel.

\subsection{Development of Dislocation Structure}

The VC and $\mathrm{Cu}$ dispersion steels should have developed different dislocation substructures during the tensile deformation due to the different particle-dislocation interactions. However, it seemed to be difficult to find a clear difference in the tensile-deformed specimens because of their rather small strains, and therefore, we observed cold-rolled specimens with a higher strain. Figure 5 shows TEM images observed from transverse direction in $\mathrm{VC}$ steel and $\mathrm{Cu}$ steel cold-rolled by $70 \%$ thickness reduction. It is confirmed in the low-magnified pictures (a) (c) that ferrite matrix of both steels is similarly elongated along the rolling direction. It should be noted that the high-magnified pictures (b) (d) show apparently different shape of particles between the two steels. VC particles keep the original shape even after severe cold deformation, while $\mathrm{Cu}$ particles are markedly elongated toward the rolling direction as well as the ferrite matrix. From the measurement of the aspect ratio distribution on transverse plane for the particles before and after cold-rolling (Fig. 6), it is found that the aspect ratio of $\mathrm{Cu}$ particle is widely distributed up to 13 . If a spherical particle is two-dimensionally deformed by $70 \%$ reduction, its aspect ratio rises to approximately 11 in theory. Therefore, the distribution of aspect ratio suggests that $\mathrm{Cu}$ particles were plastically deformed in step with the ferrite matrix, and the ferrite matrix was inhomogeneously deformed in a

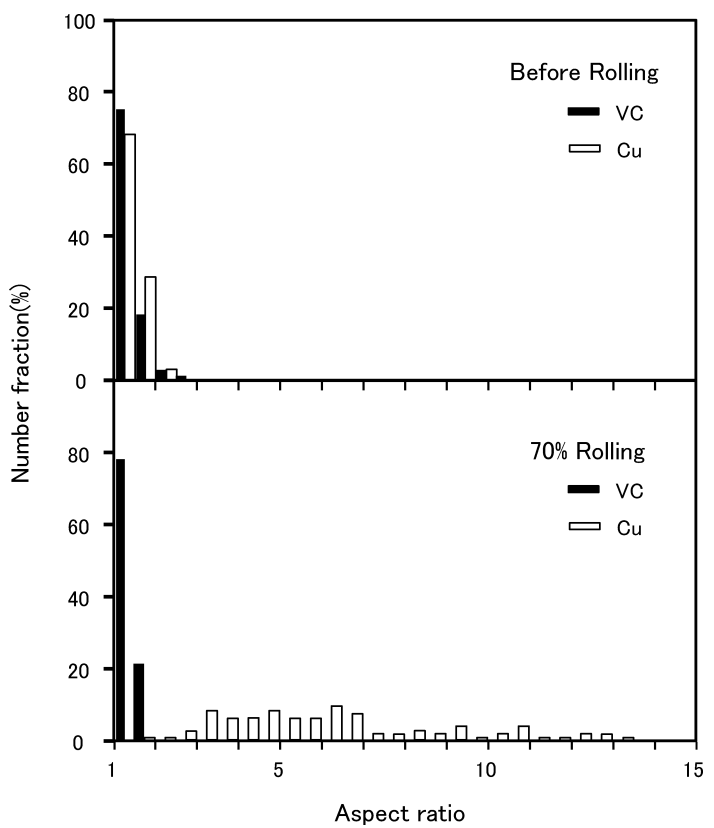

Fig. 6. Changes in distribution of aspect ratio of $\mathrm{VC}$ and $\mathrm{Cu}$ particles.

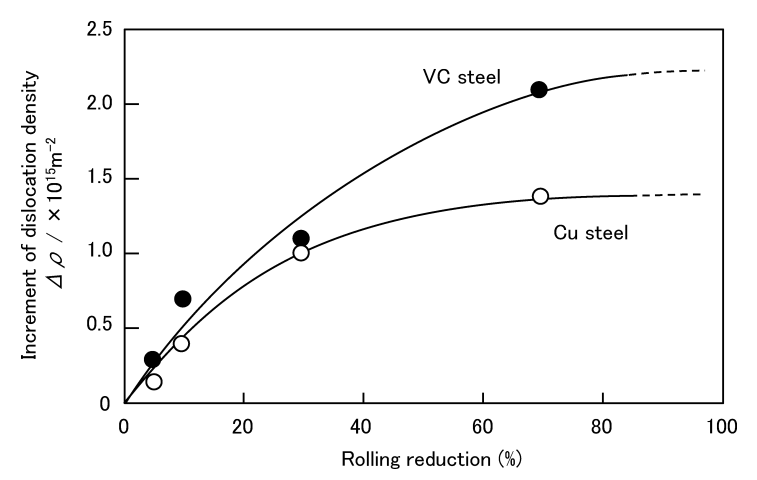

Fig. 7. Changes in dislocation density as a function of reduction by cold rolling in $\mathrm{VC}$ steel and $\mathrm{Cu}$ steel.

view of microscopic level. The plastic deformation of $\mathrm{Cu}$ particles has also an influence on the dislocation substructure in steel. In the case of hard particle dispersion like the VC steel, high-density dislocations tangle and construct a dislocation cell structure in the ferrite matrix as shown in Fig. 5(b). However, in the $\mathrm{Cu}$ steel, no dislocation tangling and no cell structure formation occur around the elongated $\mathrm{Cu}$ particles as shown in Fig. 5(d). Figure 7 shows changes in dislocation density in the $\mathrm{VC}$ steel and $\mathrm{Cu}$ steel as a function of thickness reduction by cold rolling. The dislocation density is continuously increased during deformation in both steels, but the dislocation accumulation is more pronounced in VC steel than in $\mathrm{Cu}$ steel. The difference in contribution to work hardening behavior between hard carbide and soft $\mathrm{Cu}$ particles could be explained on the basis of Ashby's theory as schematically drawn in Fig. 8. When a shear stress exceeding the critical shear stress is applied to a matrix containing spherical hard particles, dislocations in the primary slip plane bypass the particles by bowing out between them, and linking up beyond them. These dislocation loops exert the stress concentration at the particle/matrix interface (a). In this case, the stress concentration should be relieved by the nucleation and movement of pris- 


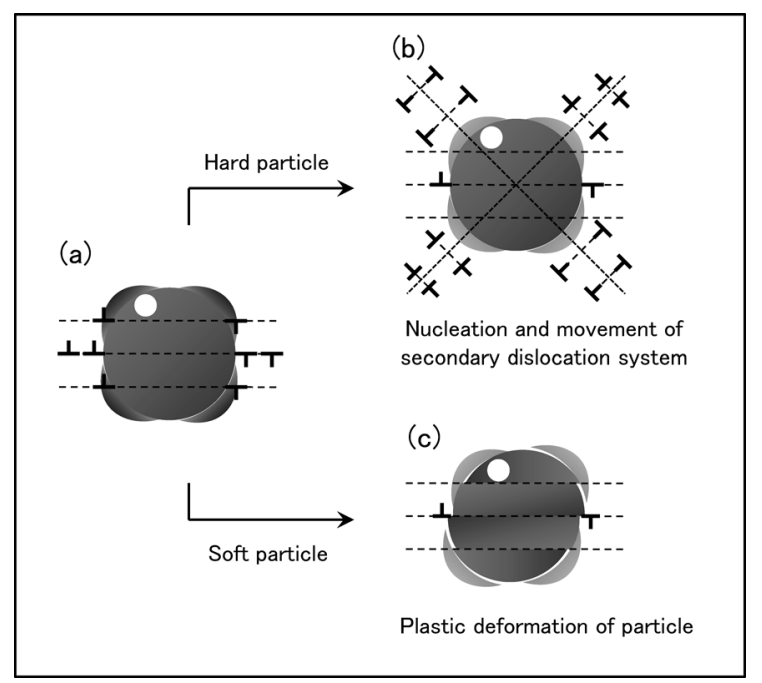

Fig. 8. Schematic illustration explaining the difference in relaxation mechanism of stress concentration at particle/matrix interface.

matic loops on secondary systems (b), which will contribute to work hardening through the increase in density of geometrically necessary dislocations leading to dislocation tangling and construction of cell structure. On the other hand, when the particles are soft enough to be plastically deformed by the shear stress, the stress concentration could be relieved without secondary dislocation systems. Therefore, the accumulation of geometrically necessary dislocations is retarded, resulting in the less work hardening rate in the $\mathrm{Cu}$ dispersion steel.

From the results obtained above, it may be concluded that the work hardening behavior of particle dispersion steels depends on not only the condition of particle dispersion such as size and volume fraction, but also the strength of particles that deeply relates with the stress relaxation behavior at the particle/interface.

\section{Conclusion}

In order to clarify the effect of soft $\mathrm{Cu}$ particle dispersion on work hardening behavior in ferritic steel, two kinds of model alloys were prepared: one is $\mathrm{Cu}$ dispersion steel $(\mathrm{Cu}$ steel) and the other is VC dispersion steel (VC steel). Tensile testing and cold rolling were carried out for these steels, and then the behaviors of work hardening and dislocation substructure development were compared. The results obtained are summarized as follows:

(1) Work hardening rate during tensile deformation is much smaller in $\mathrm{Cu}$ steel than in VC steel.

(2) The soft $\mathrm{Cu}$ particles dispersed within ferrite matrix can be plastically deformed in step with the deformation of the matrix, while the hard carbide particles can not be deformed even after severe cold deformation.

(3) In the VC steel, a high density of geometrically necessary dislocations are introduced around the carbide particles, which results in the formation of dislocation substructure characterized by high-density dislocation tangling and dislocation cells, while in the $\mathrm{Cu}$ steel, dislocation is less accumulated in comparison with the $\mathrm{VC}$ steel and no dislocation cell is formed. This difference in dislocation substructure development leads to the smaller work hardening rate in the $\mathrm{Cu}$ steel.

\section{REFERENCES}

1) K. Nakashima, Y. Futamura, T. Tsuchiyama and S. Takaki: ISIJ Int., 42 (2002), No. 12, 1541.

2) S. K. Das, A. Biswas and R. N. Ghosh: Acta Metall., 41 (1993), 777.

3) E. Orowan: Discussion in The Symposium on Internal Stresses in Metals and Alloys, Inst. Metals, London, (1948), 451.

4) G. K. Williams and R. E. Smallman: Philos. Mag., 8 (1956), 34.

5) JIS Hand Book Iron and Steel I, Japan Standard Association, Tokyo, (2006), 638.

6) Y. Kumashiro and E. Sakuma: J. Mater. Sci., 15 (1980), No. 5, 1321.

7) K. Shinohara: J. Mater. Sci., 28 (1993), No. 19, 5325.

8) M. Kato: Introduction to the Theory of Dislocations, Shokabo Press, Tokyo, (1999), 147.

9) M. F. Ashby: Philos. Mag., 14 (1966), 1157. 